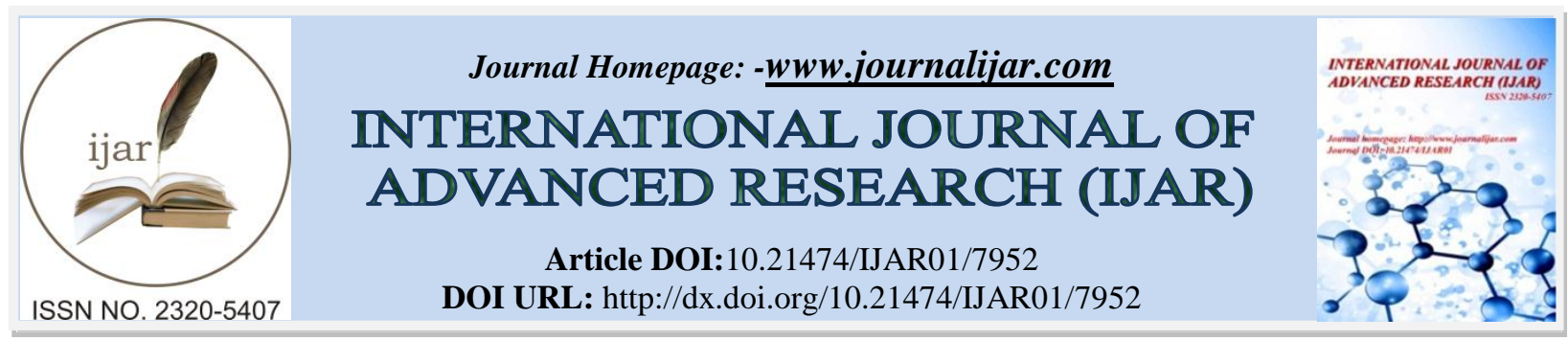

RESEARCH ARTICLE

\title{
VALUE OF ADMISSION GLYCOSYLATED HEMOGLOBIN LEVEL IN PATIENTS WITH ACUTE ST- SEGMENT ELEVATION MYOCARDIAL INFARCTION.
}

\section{Riham Elfawal ${ }^{1}$, Zizi Saad ${ }^{2}$ and Amal Kandil ${ }^{3}$.}

1. Clinical Pathology Department, Faculty of Medicine, Alexandria University/Basic Medical Science Department, Al Farabi Medical College.

2. Cardiology Department, Faculty of Medicine, Zagazig University, Egypt.

3. Medical Surgical Department, Faculty of Nursing, Alexandria University, Egypt Nursing Department, Al Farabi Faculty of Dentistry and Nursing.

\section{Manuscript Info}

Manuscript History

Received: 17 August 2018

Final Accepted: 19 September 2018

Published: October 2018

\section{Abstract}

Copy Right, IJAR, 2018. All rights reserved.

\section{Introduction: -}

Stress hyperglycemia in STEMI patients was associated with significantly increased rates of mortality and congestive heart failure and shock. Most of these studies, however were in trials of fibrinolytic therapy, conversely the evidence linking hyperglycemia with an adverse prognosis in patients treated with primary percutaneous coronary intervention (PCI) is limited and derived mainly from observational registries (Planner et al., 2013)

In AMI, stress hyperglycemia commonly occurs secondary to increased catecholamine levels, due to stress hyperglycemia so, looking only at plasma glucose levels at the time of an AMI can't predict the prognosis. (Cakmak etal.,2008).

Glycosylated hemoglobin ( $\mathrm{HbAlc}$ ) beyond its role in diagnosis of diabetesmellitus, itis a marker of long-term glycemic control and elevated $\mathrm{HbAlc}$ is associated with an increased risk of cardiovascular diseases in patients with diabetes, HbA1c is also associated with all cause mortality and cardiovascular disease even in absence of diabetes (Naito et al., 2013).

\section{Aim of the work}

Our study aimed to assess predictive value of $\mathrm{HbA1c}$ level in patients presented to Zagazig university hospital by acute STEMI treated either with thrombolytic therapy or primary angioplasty, on shortterm outcome of adverse cardiac events and outcome of PCI.

\section{Patients and method}

The study included 60 patients with Acute STEMI patient'scandidate for reperfusion therapy admitted in cardiology department Zagazig university hospital in 2013. 


\section{Inclusion criteria:}

Acute STEMI, patients with clinical presentation of STEMI within $12 \mathrm{~h}$ of symptom onset and with persistent STsegment elevation or new or presumed new LBBB, early mechanical 1ry PCI or pharmacological reperfusion should be performed as early as possible.

Patients were classified into 3 groups according to $\mathrm{HbA} 1 \mathrm{c}$ level

1. Group (1): HbA1c level 4.5 to 6.4 (non-diabetic)

2. Group (2): HbA1c level 6.5 to 8.5 (possibelydiabetic)

3. Group (3): HbA1c level more than 8.5 (diabetic)

(Hadjadj et al, 2004)

\section{Exclusion criteria:}

1. Passed time MI (If patients presented by symptoms more than 24hours).

2. Patients who have undergone rescue PCI.

3. Patients presented by NSTEMI or unstable angina.

4. Patients who have contraindication to dye as dye allergy, renal failure.

5. Patients with chronic kidney disease, liver cell failure due to giving unreliable results leading to inaccurate HbA1c level.

6. Red cell turnover, such as congenital or acquired haemolyticanaemia, chronic malaria, severe iron deficiency anaemia, recent blood donation and major blood loss (after surgery), will lead to spurious HbA1c level.

7. Concomitant use of many drugs to treat patients with malignancies, HIV or hepatitis $\mathrm{C}$ virus infection, may have a glycated hemoglobin- lowering effect.

8. Alcoholism, supplementation with vitamins $\mathrm{C}$ and $\mathrm{E}$, erythropoietin treatment, and chronic ingestion of salicylates, is also known to reduce the level of $\mathrm{HbA1c}$.

9. Vitamin B12 or folate deficiency, make HbA1c higher level than expected.

\section{All patients then were subjected to:}

Full history taking:

1. Demographic data including age, sex.

2. Detailed medical and cardiac historyincluding:

3. Diagnosis of acute MI was done on the basis of: at least two of the following

4. Typical chest pain $\geq 20$ minute, or atypical chest pain with suggestion of acute coronary syndrome.

5. ECG finding as (ST segment elevation $>2 \mathrm{~mm}$ in two contagious precordial leads or ST segment elevation $\geq$ $1 \mathrm{~mm}$ in two contagious limb leads, hyper acute $\mathrm{T}$ wave or new onset LBBB with Ischemic evidence.

6. Positive Cardiac enzymes and troponin.

7. History of ischemic heart disease.

8. Through physical examination including:

9. Resting 12 lead electrocardiography, Cardiac enzymes, and Blood sugar measurement:

10. Patient is diagnosed to be diabetic when:

11. History of diabetes, either type 1 or type 2 .

12. $\mathrm{FBG} \geq 126 \mathrm{mg} / \mathrm{dl}(7.0 \mathrm{mmol} / \mathrm{l})$.

13. 2 -h postprandial glucose $\geq 200 \mathrm{mg} / \mathrm{dl}(11.1 \mathrm{mmol} / \mathrm{l})$

14. In a patient with classic symptoms of hyperglycemia or hyperglycemic crisis a random plasma glucose $\geq 200$ $\mathrm{mg} / \mathrm{dl}(11.1 \mathrm{mmol} / \mathrm{l})($ ADA 2010).

\section{HbA1c measurement:}

Blood sample was taken within $24 \mathrm{~h}$ from admission

HbAlc cut off point for diagnosis of diabetes is $\geq 6.5 \%$ ( $48 \mathrm{mmol} / \mathrm{mol}$ ), the testwas performed in a laboratory using a method that is National Glycohemoglobin Standardization Program (NGSP). Diagnosis should be confirmed with a repeat HbA1c test, unless clinical symptoms and plasma glucose levels >200mg/dl are present (ADA, 2010).

\section{Angiography:}

1. Invasive intervention was done either at admission by (1ry PCI) or CA was done within month (3-28 days) from taking thrombolytic therapy in stable asymptomatic patients (Hochman et al., 2006).

2. 45 cases where subjected to (1ry PCI) and 15 cases receivedthrombolytic, then coronary angiography were done within one month in patients received thrombolytic therapy. 
3. For primary PCI wiring culprit artery based upon ECG, revascularization of culprit artery only was done unless patient in cardiogenic skoch(Wigins et al., 2010).

4. We use the visual method for evaluation and assessment of number of significant diseased coronary arteries, with special focus on infracted related artery (guided by ECG) on type of the lesion either type A, B, C (Ryan et al;1988)

5. Also, we used TIMI flow grading system in primary PCI cases

Follow up period:

Was done six months after the onset of MI mainly for:

1. Heart failure according to Killip class classification.

2. Reinfarction.

3. Mortality.

4. Stroke.

5. Ventricular tachyarrhythmias.

Through phone calls followed by hospital visit in outpatient clinic

\section{Statistical analysis}

Statistical presentation and analysis of the present study was conducted, using the mean, standard deviation, analysis of variance [ANOVA] test and chi-square test by SPSS V 21, students " $t$ " test was used to test the significance of the difference between two independent sample means, value of $<0.05$ indicates a significant result.

\section{Results: -}

Demographic data:

there was no significant difference between the three groups regarding age, sex. hypertension, smoking, family history and obesity, previous MI, previous PCI ( $\mathrm{p}$ value $>0.05$ ).

Table 1:-Shows demographic data in the study groups $(1,2 \& 3)$ according to HbAlc

\begin{tabular}{|c|c|c|c|c|c|c|c|c|}
\hline \multirow{2}{*}{\multicolumn{2}{|c|}{$\begin{array}{ll}\text { I. } & \text { VARIABLE }\end{array}$}} & \multicolumn{2}{|c|}{ Group (1) $(n=27)$} & \multirow{2}{*}{\multicolumn{2}{|c|}{ A. Group (2) $(\mathrm{n}=17)$}} & \multicolumn{2}{|c|}{$\begin{array}{l}\text { B. } \operatorname{Group}(3) \text { No } \\
(\mathrm{n}=16)\end{array}$} & \multirow[t]{2}{*}{ C. P-Value } \\
\hline & & \multicolumn{2}{|c|}{$\mathrm{X} \pm \mathrm{SD}$} & & & \multicolumn{2}{|c|}{$\mathrm{X} \pm \mathrm{SD}$} & \\
\hline \multicolumn{2}{|l|}{ D. Age } & \multicolumn{2}{|c|}{$57.9 \pm 10.2$} & \multicolumn{2}{|c|}{$58.3 \pm 7.1$} & \multicolumn{2}{|c|}{$57.3 \pm 8.5$} & 0.94 \\
\hline & & $\mathbf{N}$ & $\%$ & $\mathbf{N}$ & $\%$ & $\mathbf{N}$ & $\%$ & \\
\hline \multirow[t]{2}{*}{ Gender } & Female & 4 & $14.8 \%$ & 4 & $23.9 \%$ & 4 & $25 \%$ & \multirow{2}{*}{$\begin{array}{l}0.67 \\
\text { N.sig }\end{array}$} \\
\hline & Male & 23 & $85.2 \%$ & 13 & $76.5 \%$ & 12 & $75 \%$ & \\
\hline \multicolumn{2}{|l|}{ HTN } & 13 & $48.1 \%$ & 8 & $47.1 \%$ & 11 & $68.8 \%$ & $\begin{array}{l}0.35 \\
\text { N.sig }\end{array}$ \\
\hline \multicolumn{2}{|l|}{ Smoker } & 15 & $55.6 \%$ & 8 & $47.1 \%$ & 6 & $37.5 \%$ & $\begin{array}{l}0.51 \\
\text { N.sig } \\
\end{array}$ \\
\hline \multicolumn{2}{|c|}{ Family history } & 3 & $11.1 \%$ & $\mathbf{0}$ & $0 \%$ & 3 & $18.8 \%$ & $\begin{array}{l}0.19 \\
\text { N.sig }\end{array}$ \\
\hline \multicolumn{2}{|l|}{ Obesity } & 2 & $7.4 \%$ & 2 & $11.8 \%$ & 2 & $12.5 \%$ & $\begin{array}{l}\mathbf{0 . 8 3} \\
\text { N.sig }\end{array}$ \\
\hline \multicolumn{2}{|c|}{ Previous MI } & $\mathbf{0}$ & 0\% & 2 & $11.8 \%$ & 3 & $18.8 \%$ & $\begin{array}{l}\mathbf{0 . 0 8 3} \\
\text { N.sig } \\
\end{array}$ \\
\hline \multicolumn{2}{|c|}{ Previous PCI } & $\mathbf{0}$ & $0 \%$ & 1 & $5.8 \%$ & 2 & $12.5 \%$ & $\begin{array}{l}\text { 0.06 } \\
\text { N.sig }\end{array}$ \\
\hline
\end{tabular}


Table 2:-show number and \% patients who had undergone 1ry PCI or received thrombolytic therapy in the study groups $(1,2 \& 3)$ according to $\mathrm{HbA1C}$

\begin{tabular}{|c|c|c|c|c|c|c|c|}
\hline \multirow[t]{3}{*}{ II. VARIABLE } & \multicolumn{2}{|c|}{ Group (1) (n=27) } & \multicolumn{2}{|c|}{ A. Group } & \multicolumn{2}{|c|}{$\begin{array}{l}\text { B. } \\
(\mathrm{n}=16)\end{array}$} & \multirow[t]{3}{*}{ C. $\mathrm{P}-\mathrm{V}$ alue } \\
\hline & \multicolumn{2}{|c|}{$\mathrm{X} \pm \mathrm{SD}$} & \multicolumn{2}{|c|}{$X \pm S D$} & \multicolumn{2}{|c|}{$X \pm S D$} & \\
\hline & $\mathbf{N}$ & $\%$ & $\mathbf{N}$ & $\%$ & $\mathbf{N}$ & $\%$ & \\
\hline 1ry $\mathrm{PCl}$ & 18 & $66.6 \%$ & 17 & $100 \%$ & 10 & $62.5 \%$ & $\begin{array}{l}0.05 \\
\text { N.sig }\end{array}$ \\
\hline Thrombolytic therapy & 9 & $33.3 \%$ & 0 & $0 \%$ & 6 & $37.5 \%$ & $\begin{array}{l}0.78 \\
\text { N.sig }\end{array}$ \\
\hline
\end{tabular}

There was no statistically significant difference between three groups regarding type of reperfusion ( $\mathrm{p}$ value $>0.05$ ).

\section{Number of diseased vessels}

\section{Group 1:-}

20 patients $(74.1 \%)$ have single vessel disease, 4 patients (14.8\%) have two vessel disease, 3 patients (11.1\%) have three vessel disease

\section{Group 2:-}

13 patients $(76.4 \%)$ have single vessel disease, 2 patients (11.8\%) have two vessel disease and 2 patients $11.8 \%$ have three vessel disease

\section{Group 3:-}

1 patient (6.2\%) has single vessel disease,6 patients (37.5\%) had two vessel disease and 9 patients (56.3\%) have three vessel disease

Regarding single vessel disease there was highstatistically significant difference between the three groups ( $\mathrm{p}$ value $<0.001)$.

Regarding three vessel diseasethere was high statistically significant difference between the three group ( $\mathrm{p}$ value $<0.001)$.

Table 3:-show number of diseased vessels in the study groups $(1,2 \& 3)$

\begin{tabular}{|l|l|l|l|l|}
\hline Variable & $\begin{array}{l}\text { Group (1) } \\
\mathrm{n}=27\end{array}$ & $\begin{array}{l}\text { Group (2) } \\
\mathrm{n}=17\end{array}$ & $\begin{array}{l}\text { Group (3) } \\
\mathrm{n}=16\end{array}$ & Sig \\
\hline Single vessel disease & $20(74.1 \%)$ & $13(76.4 \%)$ & $1(6.2 \%)$ & 0.000 \\
\hline Two vessel disease & $4(14.8)$ & $2(11.8 \%)$ & $6(37.5 \%)$ & 0.12 \\
\hline Three vessel disease & $\mathbf{3 ( 1 1 . 1 \% )}$ & $2(11.8 \%)$ & $9(56.3 \%)$ & 0.001 \\
\hline
\end{tabular}


Figure 1:-shows show number of diseased vessel in the study group $(1,2 \& 3)$

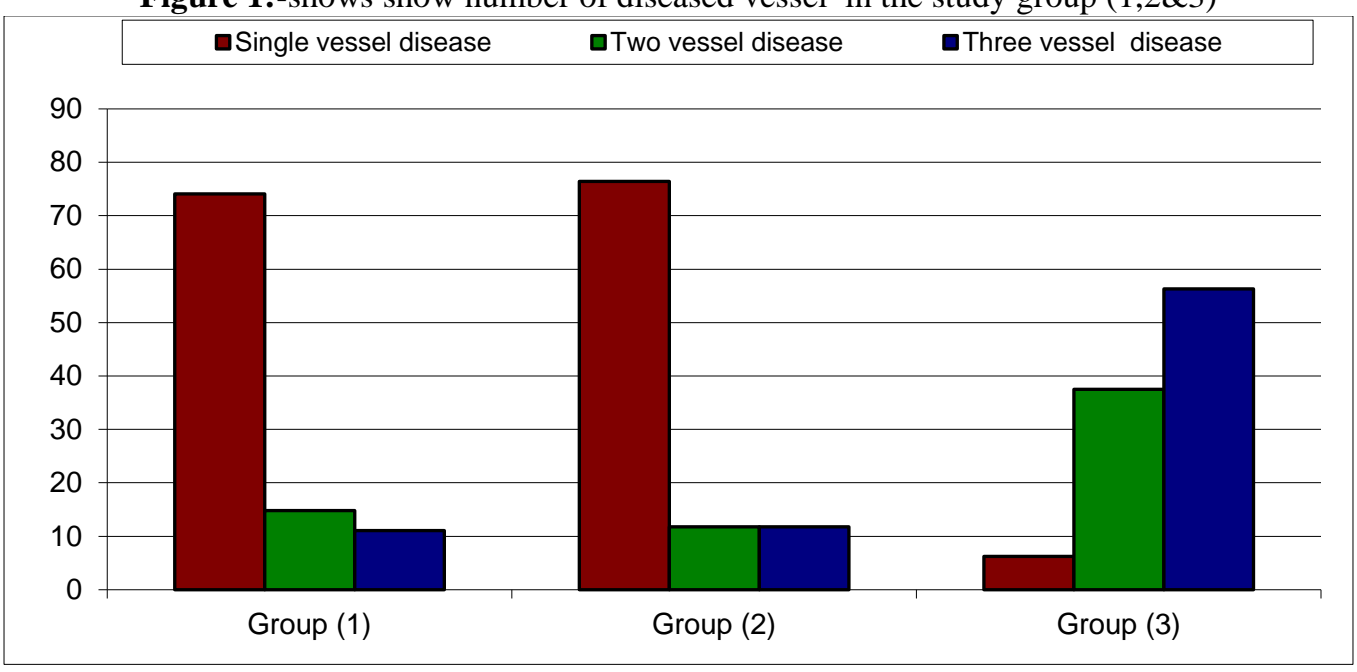

Lesion type in the study group $(1,2 \& 3)$ according HbA1c

Group 1:-

19 patients (70.4\%) have type A lesion, 5 patients (18.5\%) have type B lesion and 3 patients (11.1\%) had type C lesion.

\section{Group 2:-}

6 patients (35.3\%) have type A lesion, 9 patients (52.9\%) have type B lesion and 2 patients (11.8\%) have type C lesion

\section{Group 3:-}

3 patients (18.8\%) had type A lesion, 3 patients (18.8\%) have type B lesion and 10 patients $(62.5 \%)$ had type C lesion.

There was high statistically significant difference between the three groups regarding lesion type A, B and C p value (0.000)

Table 4: -shows lesion type in relation to the study groups according to HbA1c

\begin{tabular}{|l|l|l|l|l|}
\hline Lesion type & $\begin{array}{l}\text { Group (1) } \\
n=27\end{array}$ & $\begin{array}{l}\text { Group (2) } \\
n=17\end{array}$ & $\begin{array}{l}\text { Group (3) } \\
n=16\end{array}$ & Sig \\
\hline A & $19(70.4 \%)$ & $6(35.3 \%)$ & $3(18.8 \%)$ & 0.000 \\
B & $5(18.5 \%)$ & $9(52.9 \%)$ & $3(18.8)$ & High. sig \\
\hline C & $3(11.1 \%)$ & $2(11.8 \%)$ & $10(62.5 \%)$ & \\
\hline
\end{tabular}




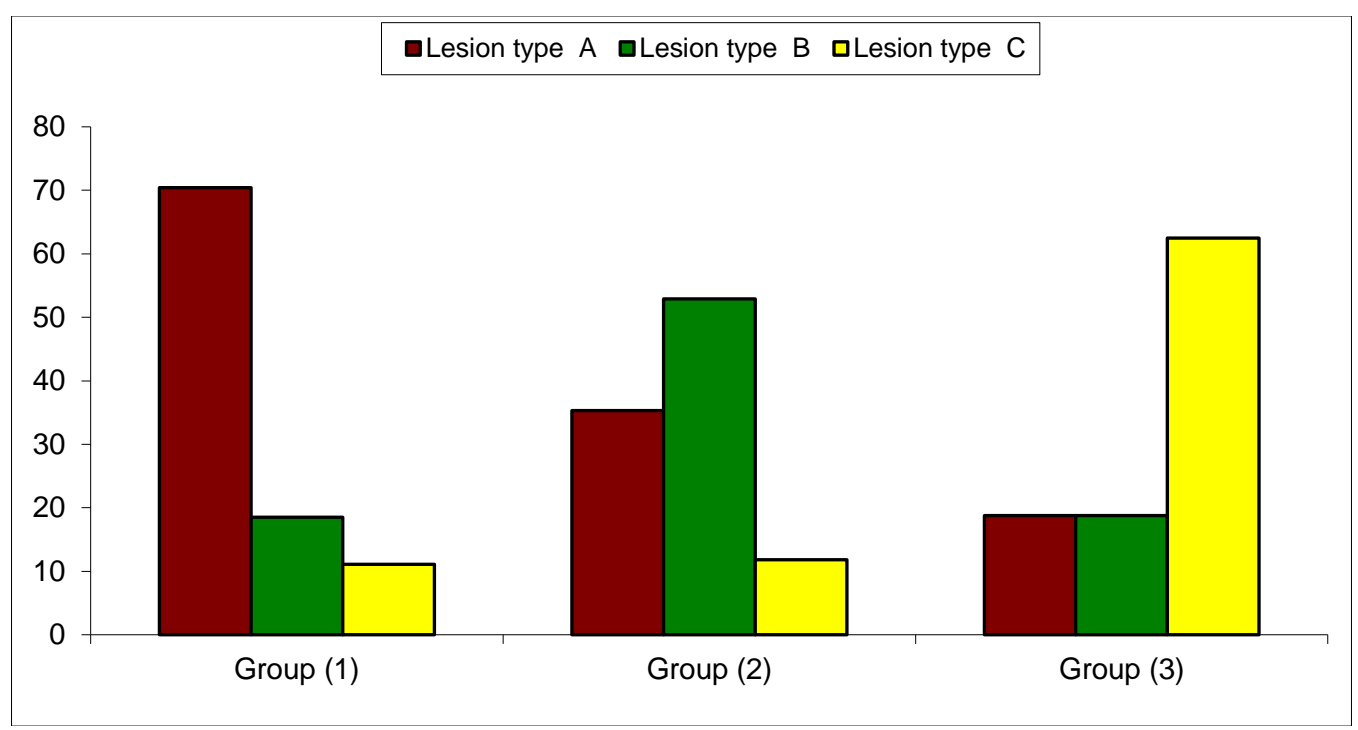

Figure 2: -shows lesion type in relation to the study groups according to HbA1c

TIMI flow in patients who had undergone primary PCI:

Table 5:-shows TIMI flow grade in primary PCI cases $(n=45)$

\begin{tabular}{|c|c|c|c|c|c|}
\hline $\begin{array}{l}\mathrm{N}=\quad \text { Patients } \\
\text { undergone 1ryPCl in } \\
\text { each group of } \mathrm{HbA1C}\end{array}$ & TIMI 0 & TIMI 1 & TIMI 2 & TIMI 3 & Sig \\
\hline Group (1) =18 & $3(16.7 \%)$ & $3(16.7 \%)$ & $3(16.7 \%)$ & $9(50 \%)$ & \multirow[t]{3}{*}{0.04} \\
\hline Group (2) =17 & $1(5.9 \%)$ & $2(11.8 \%)$ & $6(35.5)$ & $8(47.1 \%)$ & \\
\hline Group (3) =10 & $1(10 \%)$ & $6(60 \%)$ & $1(10 \%)$ & $2(20 \%)$ & \\
\hline
\end{tabular}

There was statistically significant difference between the three groups regarding TIMI flow value $<0.05$

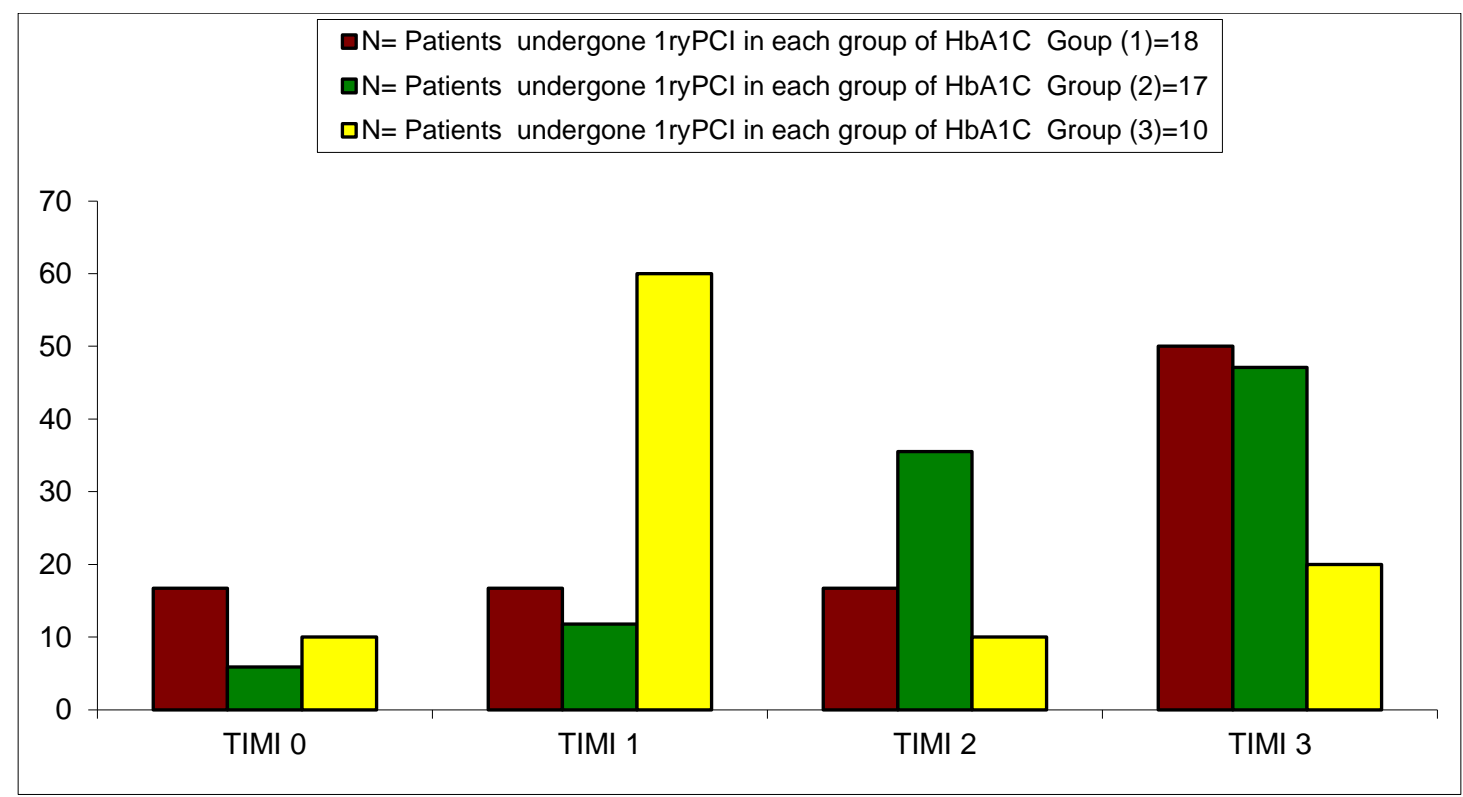

Figure 3: -shows TIMI flow grade in primary PCI cases $(\mathrm{n}=45)$ 
Table 6:-shows groups $(1,3)$ cross tabulation with TIMI 1:

\begin{tabular}{|c|c|c|c|c|c|c|}
\hline \multirow{2}{*}{\multicolumn{3}{|c|}{ Groups }} & \multicolumn{2}{|l|}{ TIMI1 } & \multirow{3}{*}{\begin{tabular}{|l|} 
Total \\
18 \\
\end{tabular}} & \multirow[t]{3}{*}{ Sig } \\
\hline & & & \multirow{2}{*}{$\begin{array}{l}\text { NO } \\
15\end{array}$} & \multirow{2}{*}{$\begin{array}{l}\text { YES } \\
\mathbf{3}\end{array}$} & & \\
\hline & 1.00 & Count & & & & \\
\hline & & $\%$ within group & $83.3 \%$ & $16.7 \%$ & $100.0 \%$ & $\begin{array}{l}0.019 \\
\text { N.sig }\end{array}$ \\
\hline & 3.00 & Count & 4 & 6 & 10 & \\
\hline & & \% within group & $40.0 \%$ & $60.0 \%$ & $100.0 \%$ & \\
\hline \multicolumn{2}{|l|}{ Total } & Count & 19 & 9 & 27 & \\
\hline
\end{tabular}

There was statistically significant difference between the group (1, 3) regarding TIMI 1, with higher percentage in favor of group 3, value $<0.05$

Cardiovascular events in the period of follow up in the study group $(1,2 \& 3)$ according to HbA1c Group (1):

2 patients $(7.4 \%)$ suffered from reinfarction, 2 patients $(7.4 \%)$ were died, 1 patient $(3.7 \%)$ suffered from heart failure, 22 patients $(81.5 \%)$ didn't suffered from any events

\section{Group (2):}

1 patient (5.9\%) suffered from reinfarction, 2 patients (11.8\%) were died, 1 patient (5.9\%) suffered from heart failure, and 13 patients $(76.5 \%)$ didn't suffer from any events

Group (3):

2 patients $(12.5 \%)$ suffered from reinfarction, 6 patients $(37.5 \%)$ were died, 2 patients $(12.5 \%)$ suffered from heart failure, and 6 patients (37.5\%) didn't suffer from any events

There was statistically significant difference in cardiovascular events and mortality in the study group p value $(<0.05)$,

Table 7: -shows adverse cardiac events in thestudy groups according to HbA1c:

\begin{tabular}{|c|c|c|c|c|}
\hline Cardiac Events & $\begin{array}{l}\text { Group (1) } \\
n=27\end{array}$ & $\begin{array}{l}\text { Group (2) } \\
n=17\end{array}$ & $\begin{array}{l}\text { Group (3) } \\
n=16\end{array}$ & Sig \\
\hline Re infarction & $2(7.4 \%)$ & $1(5.9 \%)$ & $2(12.5 \%)$ & \multirow{4}{*}{$\begin{array}{l}0.04 \\
\text { Sig }\end{array}$} \\
\hline Mortality & $2(7.4 \%)$ & $2(11.8 \%)$ & $6(37.5 \%)$ & \\
\hline Heart failure & $1(3.7 \%)$ & $1(5.9 \%)$ & $2(12.5 \%)$ & \\
\hline No cardiac events & $22(81.5 \%)$ & $13(76.5 \%)$ & $6(37.5 \%)$ & \\
\hline
\end{tabular}




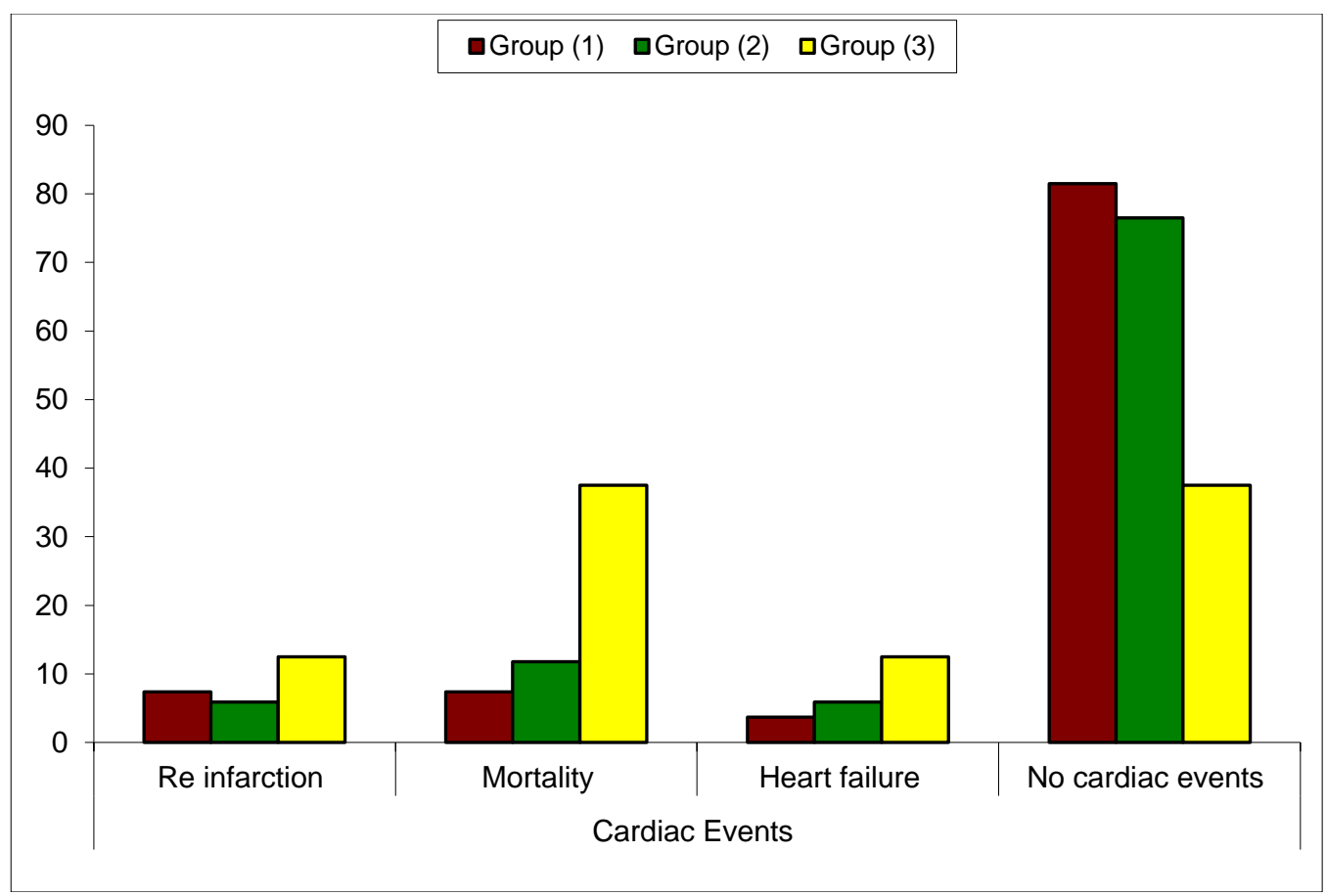

Figure 4:-shows adverse cardiac events in the study groups $(1,2 \& 3)$

The present study shows significant difference among different groups of $\mathrm{HbA} 1 \mathrm{c}$ as regard the degree of successful reperfusion. This was supported by the significant difference among different groups of HbA1c as regard TIMI flow grades in patients who have undergone mechanical reperfusion with higherpercentage of TIMI 3 in group (1)and the significant positive correlation between $\mathrm{HbA1c}$ and absent STR.

The present study shows that there was significant difference among different groups of HbAlc as regard adverse cardiac events on short term follow up period, a multi regression analysis in the present study confirmed that HbA1c over $6.5 \%$ is an independent predictor outcome of adverse cardiac events.

\section{Discussion: -}

The present study shows that in patients with acute STEMI, admissionhigher HbAlc level is associated with more severe CAD, lower ST-segment resolution,higher percentage of TMI 1 flow and lower rate of complete revascularization with TIMI 3flowafter primary angioplastyand higher incidence of mortality.

Stress hyperglycemia in STEMI patients was associated with significantly increased rates of mortality and congestive heart failure and shock, most of these studies, were in trials of fibrinolysis therapy, the evidence linking hyperglycemia with an adverse prognosis in patients treated with primary percutaneous coronary intervention (PCI) derived mainly from observational registries (Planner et al., 2013)

In the present study the peak CK-MB shows statistically significant difference among different HbA1c groups with higher mean peak CK-MB in group (3) withstatistically significant positive correlation between peak CK-MB and HbA1c ( $r=0.771, \mathrm{p} 0.00)$. This goes with the fact that hyperglycemia with STEMI is associated with significantly larger enzymatic infarct size beyond the fact that the stress response with higher catecholamines, cortisol, cytokines and TNF- $\alpha$ lead to more extensive myocardial damage. This was concordant with (Naitoet al., 2013) who found significant difference between $\mathrm{HbA1c}$ level and peak CK-MB

In the present study there was significant difference among different HbA1c groups as regard ST- segment resolution (STR), with higher percentage of absent STR in group (3), with statisticallysignificant positive correlation between HbA1c and absent STR $(r=.290, p=0.02)$. This was concordant with (Razvi et al., 2013) who found that hyperglycemia and higher HbA1c in acute STEMI is associated with impairment in ST- segment resolution, also there is a link between hyperglycemia and inadequate tissue level myocardial reperfusion. This goes with the fact 
that hyperglycemia reflect insulin deficiency which increase expression of adhesion molecules, enhance leukocyte adhesion to capillary walls and aggravate free-radical-related reperfusion injury augmenting the formation of microthrombi by increasing platelet aggregation, hyperglycemia also alter endothelium-dependent vasodilatation and impair endogenous fibrinolysis (Marfella etal., 2000) (Chen et al., 2004).

In the present study there was significant difference among different HbAlc groups as regard, number of diseased coronary vessels with higher number of three vessel disease in group (3) with statistically significant positive correlation between HbA1c and number of diseased vessel $(\mathrm{r}=3.693, \mathrm{p}=0.000)$. This was concordant with previous studies (Cakmaket al., 2008) (Kassaian et al., 2012). This goes with the fact that HbA1c increase of one percent is associated with 2.8 fold increase in CAD and in severity of coronary artery lesions, this was explained by the fact that insulin resistance in hyperglycemia promote molecular mechanism by Advanced Glycation End products (AGEs) which are intimately involved in the pathophysiology of cardiovascular disease by stimulating inflammation, contributing to atheroma formation modulating vascular stiffness and the disturbed endothelial function by reduction nitric oxide release, increased vascular smooth muscle proliferation (Prasad et al ., 2012), beyond high risk profile of those patients, it is worth mentioning that even HbAlc value in normal range is associated with presence and severity of CAD (Ashraf et al., 2013) .

On the contrary, thiswasdisconcordant with (Ertem et al., 2013) who found no significant difference between HbA1c level and severity of CAD. This discrepancy was due to that he used Gensini score for assessment of the severity CAD in his study and non-diabetic were only included in his study.

In the present study there was significant difference among different HbAlc groups as regard lesion type (A, B, C). This was concordant with (kassian et al., 2012) who found highly significant difference among HbA1c groups as regard lesion type $\mathrm{C}$. This goes with the fact that diabetes is associated with more extensive coronary artery lesion, more complex lesion more diffuse excessive toutuousity in the proximal segment, extreme angulations and total occlusion (Ryan et al., 1988).

In the present study there was significant difference among different HbA1c groups as regard TIMI flow grades in patients who had undergone 1ry PCI, with higher percentage of TIMI 3 in group (1) and significant higher percentage of TIMI 1 in favor of group (3), this finding goes with the fact that hyperglycemia is associated with higher rate of TIMI $0 \backslash 1$ and lower rate of complete revascularization TIMI 3 This was concordant with (Planner et al., 2013), this was explained by the fact that hyperglycemia adversely affect platelets function ,endothelial function, promote inflammation and result in procoagulable condition, it is worth mentioning that hyperglycemia per se in STEMI lead to impaired coronary flow on presentation and after primary PCI(Bobbertet al., 2011) . This goes with our finding that TIMI 3 complete revascularization is higher in group (1) the least level of HbA1c, and TIMI 1 flow has statistically significant difference between group (1) and (3) with higher percentage in favor of group (3) the highest level of $\mathrm{HbAlc}$, beyond that patients with higher HbAlc on admission have larger myocardial infarction and less frequently have open infracted artery.

In the present study we assess HbA1c level on the short-term outcome (six months) to detect major adverse cardiac event as mortality, heart failure and reinfarction, In the present study there was significant difference among different HbA1c groups as regard adverse cardiac events, this was concordant with previous studies (Cakmak et al., 2008) (Kassaian et al., 2012). This goes with the fact that hyperglycemia is associated with large infarct size, more hemodynamic compromise, congestive heart failure, cardiogenic shock and mortality, beyond the fact that diabeticpatients with poor glycemic control are at two-fold more risk of developing MACE, while good controlled diabetics showed lower rates comparable to non-diabetics.

In the present study there was higherpercentage of mortality in favorof group (3). This was concordant with (Cakmak et al., 2008) this goes with the fact that higher HbAlc level at admission was associated with higher baseline characteristics, largerinfarct, more extensive coronary artery lesion, lower STR, higher percentage of TMI 1 flow, lower rate of complete revascularization TIMI 3 flow

Regarding diabetes mellitus and $\mathrm{HbA1c}$, both predict adverse outcome in the present study. This was concordant with (Cakmak et al., 2008), this goes with the fact that hyperglycemia is associated with larger infarct size, lower successful response to reperfusion and high-risk profile. On the contrary, thiswasdisconcordant with (Lazzerietal., 2012), this discrepancy was due to that non-diabetic patients were only included in his study. 
The present study shows that there was significant difference between both types of reperfusion as regard complete and partial STR in favor of primary PCI, this was concordant with (Sejersten et al., 2009), this goes with the fact thatsuperiority of primary percutaneous coronary intervention over fibrinolysis, if the doortoballoon is completed in a timely fashion because TIMI 3 flow is achieved more in primary PCI patients, but we found no significant difference between both types of reperfusion regarding biochemical data, severity of CAD, outcome of adverse cardiac events . This was concordant with three previous studies (Ribichini et al., 1998) (Mehta et al., 2004) (Zijlstra et al., 1993), this was explained in our study by small sample size, which make our study not powered to detect difference between two types of reperfusion beyond short term follow up period and random selection cases according to capability of our primary PCI center.

\section{Conclusion: -}

The present study shows that admission higher HbAlc level in patients presented by acute STEMI is associated with more severe CAD, lower ST-segment resolution, lower rate of complete revascularization TIMI 3 and higher incidence of mortality.

Higher HbA1c level should be considered for risk stratification of patients presented by acute STEMI who are amenable to primary PCI

\section{References: -}

1. ADA Position Statement; Standards of Medical Care in Diabetes - 2010. Diabetes Care; 33(Suppl-1): S11-61.

2. Ashraf H, Boroumand MA, Amirzadegan A., et al (2013): Hemoglobin A1C in non-diabetic patients: An independent predictor of coronary artery disease and its severity. Diabetes Res Clin Pract. 5872;(8).

3. BobbertP, Eisenriech A, Weithäuser A., etal (2011): Leptin and resistin induce increased procoagulability in diabetes mellitus. Cytokines; 56 (2): 332-337.

4. Cakmak M, Cakmak N, Cetemen S., et al (2008): The value of admission glycosylated hemoglobin level in patients with acute myocardial infarction. Can J Cardiol. ;24(5):375-378.

5. Chen LX, Wang XF, Nanda NC., et al (2004): Real-time three-dimensional myocardial contrast echocardiography in assessment of myocardial perfusion defects. Chin Med J 2004; 117: 337-341.

6. Hadjadj S, Coisne D, Mauco G, et al. (2004) Prognostic value of admissionplasma glucose and HbA in acute myocardial infarction. DiabetMed2004; 21:305-10.

7. Hochman JS, Lamas GA, Buller CE., et al (2006): Coronary intervention for persistent occlusion after myocardial infarction. N Engl J Med; 355 (23):2395-2407.

8. Kassaian SE, Goodarzynejad H, Boroumand MA., et al (2012):Glycosylated hemoglobin (HbA1c) levels and clinical outcomes in diabetic patients following coronary artery stenting. Cardiovasc Diabetol. 17; (11): 82.

9. Lazzeri C, Valente S, Chiostri M., et al (2012):Glycated hemoglobin in ST-elevation myocardial infarction without previously known diabetes: its short- and long-term prognostic role. Diabetes Res Clin Pract.; 95(1):146.

10. Marfella R, Esposito K, Giunta R, et al (2000): Circulation adhesion molecules in humans: role of hyperglycemia and hyperinsulinemia. Circulation; 101: 2247-2251.

11. Mehta L, Devlin W, McCullough PA., et al (2007):Impact of body mass index on outcomes after percutaneous coronary intervention in patients with acute myocardial infarction. Am J Cardiol.; 99 (7):906-910.

12. Mehta RH, Sadiq I, Goldberg RJ., et al (2004):Effectiveness of primary percutaneous coronary intervention compared with that of thrombolytic therapy in elderly patients with acute myocardial infarction. Am Heart J. ;147(2):253-259.

13. Mehta RH, Starr AZ, Lopes RD., et al (2011):Relationship of sustained ventricular tachyarrhythmias to outcomes in patients undergoing primary percutaneous coronary intervention with varying underlying baseline risk. Am Heart J.; 161(4):782-789.

14. Naito R, Miyauchi K, Ogita M., et al (2013):Impact of admission glycemia and glycosylated hemoglobin A1c on long-term clinical outcomes of non-diabetic patients with acute coronary syndrome. J Cardiol. ;740 (6):234238.

15. Planer D, Witzenbichler B, Guagliumi G., et al (2013): Impact of hyperglycemia in patients with ST-segment elevation myocardial infarction undergoing percutaneous coronary intervention: the HORIZONS-AMI trial. Int J Cardiol. ;167(6):2572-2579.

16. Prasad A, Bekker P and Tsimikas S. (2012): Advanced glycation end products and diabetic cardiovascular disease. Cardiol Rev. ;20 (4):177-183. 
17. Prasad A, Stone GW, Aymong E., et al (2004):Impact of ST-segment resolution after primary angioplasty on outcomes after myocardial infarction in elderly patients: an analysis from the CADILLAC trial. Am HeartJ.; 147(4):669-675.

18. Razvi N, Grundy B, Ng L., et al (2013): larger infarct size associated with dysglycemia at the time of STelevation myocardial infarction is related to later presentation. J Cardiovasc MagnReson., 15 (1): 077

19. Ribichini F, Steffenino G, Dellavalle A., et al (1998): Comparison of thrombolytic therapy and primary coronary angioplasty with liberal stenting for inferior myocardial infarction with precordial ST-segment depression: immediate and long-term results of a randomized study. J Am Coll Cardiol. ;32(6):1687-1694.

20. Ryan TJ, Faxon DP, Gunnar RM., et al (1988): Guidelines for percutaneous transluminal coronary angioplasty. A report of the American College of Cardiology/American Heart Association Task Force on Assessment of Diagnostic and Therapeutic Cardiovascular Procedures (Subcommittee on Percutaneous Transluminal Coronary Angioplasty). Circulation; 78 (2):486-502.

21. Sejersten M, Valeur N, Grande P., et al (2009): Long-term prognostic value of ST-segment resolution in patients treated with fibrinolysis or primary percutaneous coronary intervention results from the DANAMI-2 (DANish trial in acute myocardial infarction-2). J Am Coll Cardiol.; 54(19):1763-1769.

22. Wijns W, Kolh P, Danchin N., et al (2010):Guidelines on myocardial revascularization. Task Force on Myocardial Revascularization of the European Society of Cardiology (ESC) and the European Association for Cardio-Thoracic Surgery (EACTS); European Association for Percutaneous Cardiovascular Interventions (EAPCI),Eur Heart J.; 31(20):2501-2555.

23. Zijlstra F, de Boer MJ, Hoorntje JC., et al (1993):A comparison of immediate coronary angioplasty with intravenous streptokinase in acute myocardial infarction. N Engl J Med.; 328(10):680-684. 